УДК 911.2:911.52(571.54)

ЛАНДШАФТООБРАЗУЮЩИЕ ФАКТОРЫ В ГОЛЬЦОВОМ

И НИВАЛЬНО-ГЛЯЦИАЛЬНОМ ПОЯСАХ ЮЖНОЙ ЧАСТИ

БАРГУЗИНСКОГО ХРЕБТА

Белоусов В.Ю., Лопатина Д.Н.

Институт географии им. В.Б. Сочавы СО РАН, Иркутск, е-mail: belousov.tdutybz2017@yandex.ru

\begin{abstract}
В данной статье представлены результаты комплексной ландшафтно-географической экспедиции, проведенной в летний полевой сезон 2017 г. в районе южной части Баргузинского хребта на особо охраняемой природной территории (Забайкальский национальный парк), поэтому тема является актуальной и важной, имеет научное и прикладное значение. В ходе данной экспедиции были проведены полевые описания почв, растительности и процессов и факторов ландшафтообразования в труднодоступной гольцовой и нивальногляциальной зонах на территории исследования. Предварительно изучены физико-географические условия исследуемого района, а также методы исследований. В ходе полевых работ изучены и описаны условия и факторы ландшафтообразования в гольцовом и нивально-гляциальном поясах: нивация, солифлюкция, денудация, десерпция, аккумуляция, наличие снежников и их влияние на процесс ландшафтообразования - и представлены в статье. Гольцы, по сравнению с тайгой, слабо закреплены или вовсе не закреплены растительным покровом, именно поэтому в таких районах среди ландшафтообразующих факторов главная роль отводится современным экзогенным процессам. В гольцовом и нивально-гляциальном поясах Баргузинского хребта широко распространены снежники, играющие ощутимую рельефообразующую и стокоформирующую роль, но им при изучении обычно уделяют меньше внимания, чем ледникам. Однако изучение снежников является важным по многим причинам: снежники быстро реагируют на климатические изменения, являясь даже более четкими их индикаторами, чем ледники, а также снежники - это источники воды, они могут играть важную роль в формировании стока, как и ледники, и т.д. В дальнейшем планируется провести многолетнюю динамику факторов ландшафтообразования в районе Баргузинского хребта и других гор Юго-Восточной Сибири.
\end{abstract}

Ключевые слова: факторы ландшафтообразования, гольцовый пояс, нивально-гляциальный пояс, Баргузинский хребет, особо охраняемая природная территория

\title{
LANDSCAPE FORMING FACTORS IN THE LOACH AND NIVAL-GLACIAL BELTS OF THE SOUTHERN PART OF BARGUZIN RANGE
}

\section{Belousov V.Yu., Lopatina D.N.}

V.B. Sochava Institute of geography of the Siberian Branch of the Russian Academy of Science, Irkutsk,e-mail: belousov.tdutybz2017@yandex.ru

In this article results of the complex landscape and geographical expedition conducted to a summer field season of 2017 around the southern part of Barguzin Range in especially protected natural territory (Transbaikal national park) therefore the subject is relevant and important are provided, has scientific and applied relevance. During this expedition field descriptions of soils, vegetation and processes and factors of landscape forming in the remote loach and nival-glacial zones in the territory of a research have been carried out. Physiographic conditions of the explored area and also methods of researches are previously studied. During field works conditions and factors of landscape forming in the loach and nival-glacial belts are studied and described: nivation, solifluction, denudation, deserption, accumulation, existence of snow patch and their influence on process of landscape forming are also presented in article. Loaches, in comparison with a taiga, are poorly fixed or not fixed at all by a vegetable cover for this reason in such areas among landscape forming factors the leading role is assigned to modern exogenous processes. In loach and nival-glacial belts of Barguzin Range the snow patch playing a notable relief forming and flow forming role are widespread, but when studying usually pay them less attention, than to glaciers. However studying of snow patch is important for many reasons: snow patch quickly react to climatic changes, being even their more accurate indicators, than glaciers and also snow patch are sources of water, and can play an important role in formation of a drain, as well as glaciers, etc. Further it is planned to carry out long-term dynamics of factors of landscape forming near Barguzin Range and other mountains of Southeast Siberia.

Keywords: landscape forming factors, loach belt, nival-glacial belt, Barguzin Range, especially protected natural territory

Район исследования располагается в труднопроходимых местах на особо охраняемой природной территории, что добавляет актуальности теме работы. Ландшафты Баргузинского хребта, как и других горных систем, сформировались в результате длительного воздействия на поверхность Земли двух противоположных процессов: эндогенных и экзогенных. Эндогенные про- цессы преимущественно создают первоначальную неровность рельефа - поднимают или опускают участки земной коры, а экзогенные процессы в общем их сглаживают [1], но и расчленяют под действием отдельных групп процессов.

Гольцовый и нивально-гляциальный пояса фиксируются на высотах 1800-2800 м. В относительно невысоких горах Баргузин- 
ского хребта нивально-гляциальный пояс представлен фрагментарно, отдельными объектами - малыми ледниками, многолетними снежниками, каменными глетчерами, наледями, в формировании и изменении горных ландшафтов они играют значительную роль. Гольцовый пояс располагается выше верхнего предела распространения древесной растительности. Нижнюю часть гольцов формируют кустарники (кедровый стланик и ерники), выше по долинам рек распространены травяно-кустарничковые, мохово-лишайниковые горные тундры с частыми склоновыми накипно-лишайниковыми курумами.

Цель исследования: описание ландшафтов и исследование ландшафтообразующих процессов в гольцовом и нивально-гляциальном поясах южной части Баргузинского хребта. Гольцы, по сравнению с тайгой, слабо закреплены растительностью. Поэтому здесь среди ландшафтообразующих факторов главная роль отводится современным экзогенным процессам. На крутых склонах при отсутствии сомкнутого растительного покрова, в суровых климатических условиях, с наличием снежников развиваются процессы морозного крупнообломочного выветривания и нивации. Гравитационная денудация способствует накоплению у подножий крутых склонов грубообломочных отложений, для которых характерно вымывание подповерхностного мелкозема. В гольцах Баргузинского хребта широко распространены снежники, играющие ощутимую рельефообразующую и стокоформирующую роль, однако их исследование пока незначительно. Изучение снежников является важным по многим причинам [2].

\section{Материалы и методы исследования}

Многолетние снежники отличаются от сезонного снежного покрова тем, что они являются более устойчивыми к таянию, часто образуются в одних и тех же местах, формируют специфические формы рельефа, являются природными накопителями влаги, источниками питания водотоков и близко расположенной растительности. Изучение области распространения снежников, а также их динамики достаточно актуально для современной науки благодаря ряду свойственных им характеристик [3]. Во-первых, снежники быстро реагируют на климатические изменения, являясь даже более четкими их индикаторами, чем ледники [4]. Высотный пояс, в котором развиваются многолетние снежники, соответствует определенному сочетанию тепла и влаги, его смещение выше или ниже позволяет проследить направленность изменений климата. Подобные процессы и явления в горах юга Восточной Сибири изучались сотрудниками Института географии СО РАН [1, 5, 6]. Во-вторых, снежники являются промежуточным этапом между существованием сезонного снежного покрова и возникновением ледника. А также малые ледники могут превращаться в многолетние снежники, то есть эти процессы носят обратимый характер. Трансформация ледников в снежники и наоборот осуществляется иногда скачкообразно, это порой приводит к быстрым изменениям площади оледенения горного района, при этом общая площадь снежно-ледовой поверхности может изменяться не настолько сильно. Вот почему необходимо учитывать снежники, их недоучет может приводить к серьезным искажениям реального объема и площади снежно-ледовых ресурсов исследуемой территории [4]. В-третьих, так же как ледники, снежники - это источники воды, и они могут играть важную роль в формировании стока. В-четвертых, наличие снежников является следствием определенного соотношения тепла и влаги, их сочетание с условиями рельефа, поскольку они приурочены, как правило, к неровным, контрастным участкам, где имеются тень и повышенная концентрация твердых осадков. В связи с этим расположение снежников является закономерным, часто унаследованным от прошлых более холодных эпох, когда оледенение имело значительный масштаб и его эрозионная и аккумулятивная деятельность воздействовали на рельеф, увеличивая его контрастность. Следствием такой деятельности ледников является создание особых форм рельефа, таких как моренные валы, термокарстовые котловины, каналы маргинального стока, ригельные уступы и другие. Все эти формы рельефа активно используются снежниками. Однако снежники не только приспосабливаются к существующему рельефу, но и сами активно его трансформируют, увеличивая его резкость и контрастность, формируя такие отрицательные формы рельефа, как нивальные ниши и нивальные кары [4]. Снежники поставляют рыхлый обломочный материал, который ниже перемещается под действием солифлюкции и десерпции, формируют нивальные 
ниши, гольцовые террасы, а также эрозионно-нивальные ложбины, которые часто становятся местами схода лавин и селей. В местах скопления многолетних снежников формируются альпинотипные лужайки с влаголюбивой растительностью, меняется микроклимат, мерзлотный режим, создается особый природный комплекс. Снежники питают водотоки и создают систему стока.

При изучении ландшафтообразующих процессов в горах авторами использованы такие методы исследования, как описательный, сравнительно-географический, картографический, дистанционный, а также метод ландшафтной индикации.

\section{Результаты исследования и их обсуждение}

В период с 9.08.17. по 17.08.17. в южной части Баргузинского хребта были выполнены комплексные экспедиционные исследования. Баргузинский хребет простирается по большей части восточного побережья озера Байкал. С севера хребет ограничивается долиной Верхней Ангары и протягивается на юг на 300 км. Ширина хребта в разных местах варьируется от 30 до 80 км. В среднем высота вершин гор составляет 2400 м. Самой высокой точкой является пик Байкал (2841 м). Хребет отличается и наличием большого количества пиков, трапеций, пирамид и игл. В расчлененности рельефа хребта отмечается сравнительно недавнее оледенение, проявляющееся в виде небольших ледников разных форм. Также характерны для территории исследования долины рек трогового характера, с уступами и ригелями по всей их длине, а также многочисленные каскадные водопады. Кроме того, на платообразных частях хребта и у истоков рек часто можно встретить озера ледникового происхождения в цирках (рис. 1).

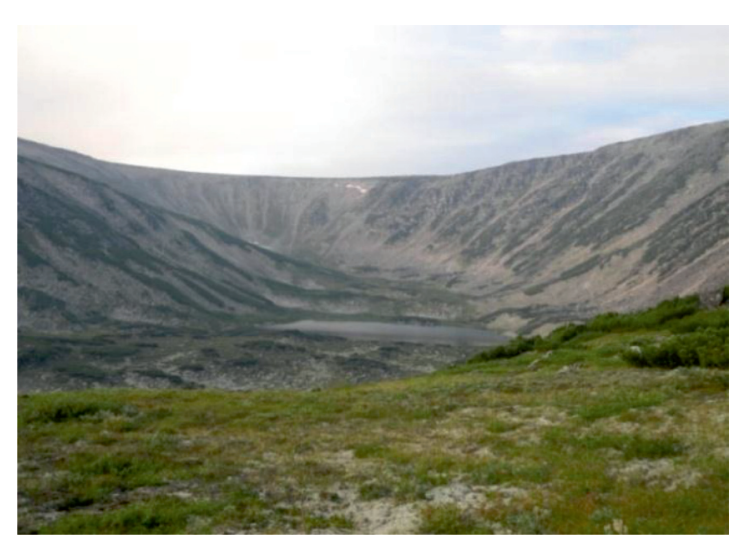

Рис. 1. Озеро Дикое (фото Д.Н. Лопатиной)

Баргузинский хребет отличается ярко выраженной растительностью. На высотах до 1200-1400 м еще преобладает таежная растительность, а с 1400 м таежный пояс переходит в горно-тундровый.

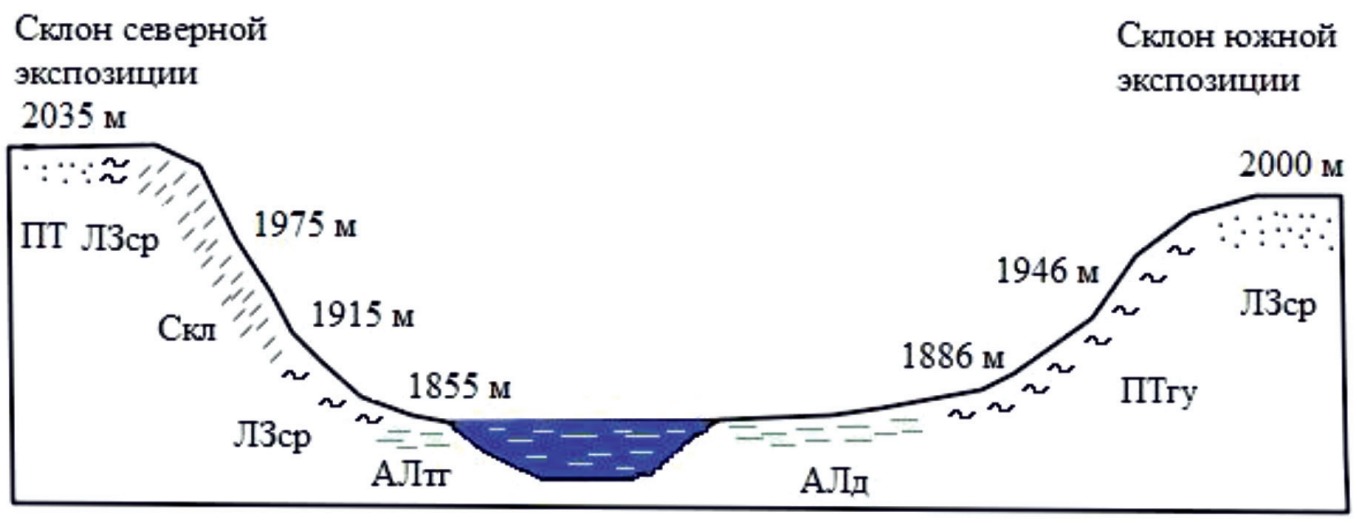

Рис. 2. Ландшафтный профиль, составленный по склонам вблизи озера Дикое. Условные обозначения:

2035 м - высота над уровнем моря. Преобладаюший тип почвы: ПТ - петроземы типичные;

ЛЗср - литоземы серогумусовые типичные; Скл - крупнообломочный крутой склон;

АЛтг - аллювиальные торфяно-глеевые типичные; АЛд-аллювиальные гумусовые (дерновые) типичные; ПТгу - петроземы гумусовые типичные. Растительность: $: \because-$ горная тундра, лишайниковая; $\approx$ - заросли кедрового стланика;

= -заболоченньй луг;" ", - крупнообломочный накипно-литайниковый склон 


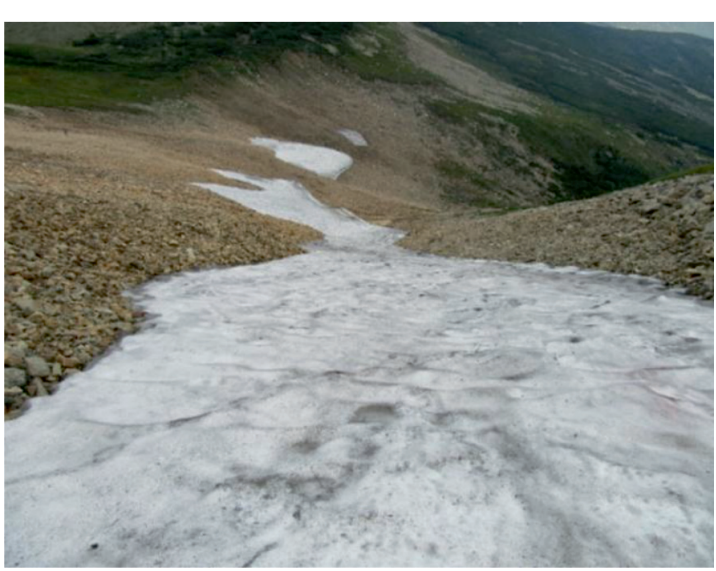

Рис. 3. Снежник, обнаруженный в истоках реки Нестериха 12.08.2017 2. (фото В.Ю. Белоусова)

Почвенный покров Баргузинского хребта весьма разнообразен в целом, а в гольцах привершинные склоны с уклоном $45^{0}$ заняты литоземами серогумусовыми типичными на гранитах и гранито-гнейсах под кедровым стлаником и злаково-брусничночернично-бодановой растительностью. Выположенные привершинные поверхности заняты дерново-подбурами иллювиальножелезистыми на гранитах и гранито-гнейсах под кустарничковой злаково-лишайниковой растительностью. На водораздельных поверхностях преобладают петроземы и петроземы гумусовые типичные на плотных гранитах и гранито-гнейсах под кедровым стлаником и горно-тундровой растительностью, литоземы серогумусовые типичные под щебнистой лишайниковой тундрой с кедровым стлаником на плотных гранитах и гранито-гнейсах (рис. 2).

В понижениях на водораздельных поверхностях преобладают аллювиальная торфяно-глеевая типичная почва под кустарничковым разнотравно-злаковым лугом на аллювиальном песке, гравии и супесях и торфяно-литоземы типичные на гранитогнейсах под заболоченной тундровой растительностью и кустарничковой злаковомохово-лишайниковой тундрой. В истоках рек вблизи горных озер преобладают аллювиальные гумусовые (дерновые) типичные на аллювиальных породах под разнотравнозлаковым заболоченным лугом и петроземы гумусовые оподзоленные на гранито-гнейсах под тундровой растительностью [7].

В ходе экспедиции были обнаружены и измерены 17 снежников, располагавших-

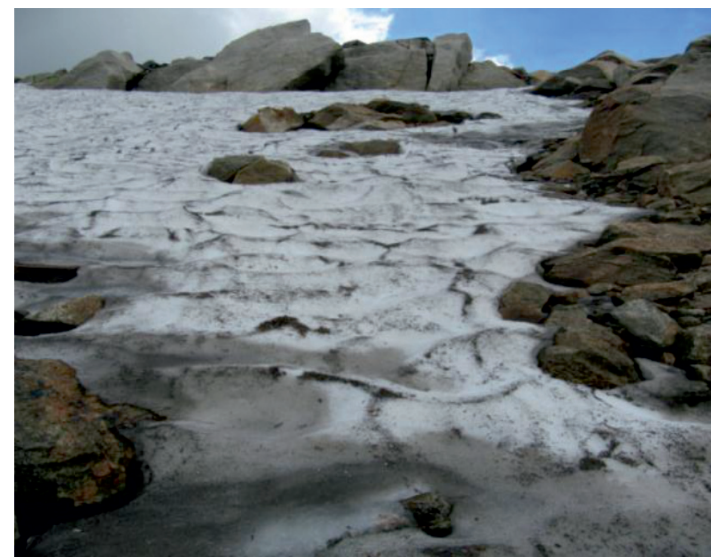

Рис. 4. Снежник, обнаруженный в истоках реки Большой Чивыркуй 13.08.2017 2. (фото В.Ю. Белоусова)

ся на высотах от 1700 до 2000 м, с площадью от 2 до 50 м², мощностью до 4 м. Крупнейший из снежников (рис. 3) расположен на водоразделе рек на северо-восточном склоне, на высоте от 1760 до 1800 м. Коор-

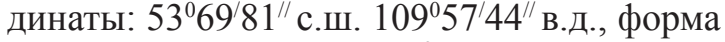
вытянутая. Площадь 50 м², со средней мощностью 4 м.

Второй по величине снежник (рис. 4) был расположен на 9 км северо-восточнее первого, на северо-восточном склоне. На высоте от 1880 до 1910 м с координатами $53^{0} 7699^{\prime \prime}$ с.ш. $109^{0} 60^{\prime} 66^{\prime \prime}$ в.д. Форма снежника овальная, площадь $40 \mathrm{M}^{2}$ со средней мощностью 3,5 м.

Третий по величине (рис. 5) расположен на 5,5 км северо-западнее второго снежника в ложбине на юго-восточном склоне, на высоте от 1850 до 1870 м. Координаты: $53^{\circ} 80^{\prime} 81^{\prime \prime}$ с.ш. $109^{0} 56^{\prime} 04^{\prime \prime}$ в.д., имеет форму полукруга. Площадь $30 \mathrm{~m}^{2}$ со средней мощностью 2,5 м.

В результате данного исследования было выявлено, что наиболее благоприятные условия для образования снежников на Баргузинском хребте наблюдаются в диапазоне высот от 1700 до 2700 м, преимущественно на северо-восточных склонах [3]. Снежники формируют нивальные ниши, гольцовые террасы, поставляют рыхлый обломочный материал, который ниже перемещается под действием солифлюкции и десерпции. В местах скопления многолетних снежников на территории Баргузинского хребта формируются альпинотипные лужайки с влаголюбивой растительностью, меняется микроклимат, мерзлотный режим, 
создается особый природный комплекс. Снежники на территории исследования питают водотоки и создают систему стока. Проводя сравнение с Восточным Саяном (район горы Мунку-Сардык), можно заключить, что современные экзогенные процессы, формирующие и преобразующие ландшафт в гольцовом и нивально-гляциальном поясах, здесь также разнообразны, среди них доминируют нивация и солифлюкция.

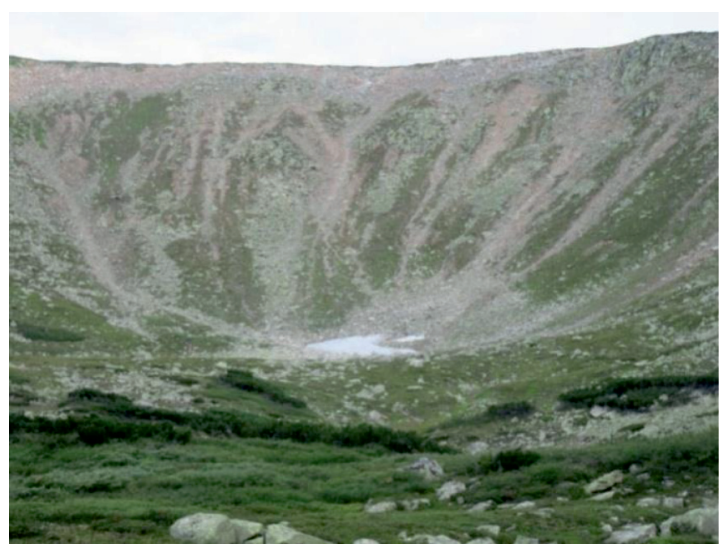

Рис. 5. Снежник, обнаруженный в истоках реки Дубари, 14.08.2017 г. (фото В.Ю. Белоусова)

\section{Заключение}

Таким образом, согласно проведенным исследованиям, ландшафтообразующая деятельность в гольцовом и нивально-гляциальном поясах Баргузинского хребта в период непосредственного наблюдения проявляется в виде небольших изменений. Основные процессы (нивация и солифлюкция) связаны с разрушением горных пород путём постоянного морозного выветривания в процессе их попеременного замерзания и оттаивания, a также с медленным передвижением по склонам почв и рыхлых грунтов. В результате чего формируются нивальные ниши, гольцовые террасы, а также эрозионно-нивальные ложбины, характерные для ландшафта гор Баргузинского хребта. В дальнейшем планируется исследовать многолетнюю динамику экзогенных процессов рельефообразования в районе Баргузинского хребта, увязать ее с изменениями климата, определить главные факторы ландшафтообразования, их интенсивность и изменчивость.

Работа выполнена при финансовой поддержке РФФИ, № 17-05-00400.

\section{Список литературы / References}

1. Плюснин В.М., Иванов Е.Н., Китов А.Д., Шейнкман В.С. Динамика современных ледников в горах юга Восточной Сибири // География и природные ресурсы. 2017. № 3. С. 118-126.

Plyusnin V.M., Ivanov E.N., Kitov A.D., Sheinkman V.S. The dynamics of contemporary glaciers in the mountains of the South of East Siberia // Geography and Natural Resources. 2017. № 3. C. 118-126 (in Russian).

2. Глушкова И.А. Снежники и их геоморфологическая роль на Западном Кавказе (северный склон): дис.... канд. геогр. наук. Краснодар, 2000. 137 с.

Glushkova of I.A. Snezhniki and their geomorphological role on Western Caucasus (a northern slope): dis.... kand. geogr. nauk. Krasnodar, 2000. 137 p. (in Russian).

3. Белоусов В.Ю., Иванов Е.Н. Снежники как компонент ландшафтообразования в горах юга Восточной Сибири // Региональные аспекты изменения природной среды и общества: материалы XIX научной конференции молодых географов Сибири и Дальнего Востока (Иркутск, 3-7 октября 2017 г.). Иркутск: Изд-во Института географии им. В.Б. Сочавы СО РАН, 2017. С. 7-8.

Belousov V.Yu., Ivanov of E.N. Snezhniki as a landshaftoobrazovaniye component in mountains of the South of Eastern Siberia // Regional aspects of change of the environment and society: materials XIX of a scientific conference of young geographers of Siberia and the Far East (Irkutsk, on October 3-7, 2017). Irkutsk: Publishing house of Institute of geography of V.B. Sochava of the Siberian Branch of the Russian Academy of Science, 2017. P. 7-8 (in Russian).

4. Ганюшкин Д.А., Москаленко И.Г., Чистяков К.В. Динамика многолетних снежников и снежно-фирновых полей массива Монгун-Тайга // Вестник СПбГУ. Серия 7. 2012. № 4. C. 164-175.

Ganushkin D.A., Moskalenko I.G., Chistyakov K.V. Dynamics of perennial snow patches and snow-firn fields of Mongun-Taiga mountain massif // Vestnik SPbGU. Seriya 7. 2012. № 4. P. 164-175 (in Russian).

5. Китов А.Д., Гладков А.С., Лунина О.В., Плюснин В.М., Иванов Е.Н., Серебряков Е.В., Афонькин А.М. Изменения мощности ледника Перетолчина (Восточный Саян) // ИНТЕРКАРТО/ИНТЕРГИС. 2017. Т. 23. № 1 . C. 405-417. DOI: 10.24057/2414-9179-2017-1-23-405-417.

6. Kitov A.D., Gladkov A.S., Lunina O.V., Plyusnin V.M., Ivanov E.N., Serebryakov E.V., Afon 'kin A.M. Changes in thickness of Peretolchin glacier (Eastern Sayan) // INTERKARTO/ INTERGIS. 2017. T. 23. № 1. P. 405-417. DOI: 10.24057/24149179-2017-1-23-405-417 (in Russian).

7. Иванов Е.Н. Динамика горных ледников на юге Восточной Сибири и Западе Монголии // Россия - Монголия: материалы Международной молодежной научнопрактической конференции. (Иркутск - Улан-Батор), 2016. C. $107-109$.

Ivanov E.N. Dynamics of mountain glaciers in the south of Eastern Siberia and the West of Mongolia // Russia - Mongolia: materials of the International youth scientific and practical conference. (Irkutsk - Ulaanbaatar), 2016. P. 107-109 (in Russian).

8. Лопатина Д.Н., Белозерцева И.А. Почвы Баргузинского хребта // Устойчивое развитие в Восточной Азии: актуальные эколого-географические и социально-экономические проблемы: материалы Международной научно-практической конференции (Улан-Удэ, 18-19 мая 2018 г.). УланУдэ: Изд-во Бурятского гос. ун-та, 2018. С. 313-316.

Lopatina D.N., Belozertseva I.A. Soils of Barguzin Range// Sustainable development in East Asia: current ekologo-geographical and social and economic problems: materials of the International scientific and practical conference (Ulan-Ude, on May 18-19, 2018). Ulan-Ude: Publishing house the Buryat state. un-that, 2018. P. 313-316 (in Russian). 